\title{
Determining the degradation efficiency and mechanisms of ethyl violet using HPLC-PDA-ESI-MS and GC-MS
}

Wen-Hsin Chung ${ }^{2+}$, Chung-Shin Lu ${ }^{3+}$, Wan-Yu Lin ${ }^{2 \dagger}$, Jian-Xun Wang ${ }^{1+}$, Chia-Wei Wu ${ }^{1+}$ and Chiing-Chang Chen ${ }^{1 *}$

\begin{abstract}
Background: The discharge of wastewater that contains high concentrations of reactive dyes is a well-known problem associated with dyestuff activities. In recent years, semiconductor photocatalysis has become more and more attractive and important since it has a great potential to contribute to such environmental problems. One of the most important aspects of environmental photocatalysis is in the selection of semiconductor materials like $\mathrm{ZnO}$ and $\mathrm{TiO}_{2}$, which are close to being two of the ideal photocatalysts in several respects. For example, they are relatively inexpensive, and they provide photo-generated holes with high oxidizing power due to their wide band gap energy. In this work, nanostructural ZnO film on the Zn foil of the Alkaline-Manganese Dioxide-Zinc Cell was fabricated to degrade EV dye. The major innovation of this paper is to obtain the degradation mechanism of ethyl violet dyes resulting from the HPLC-PDA-ESI-MS analyses.

Results: The fabrication of $\mathrm{ZnO}$ nanostructures on zinc foils with a simple solution-based corrosion strategy and the synthesis, characterization, application, and implication of $\mathrm{Zn}$ would be reported in this study. Other objectives of this research are to identify the reaction intermediates and to understand the detailed degradation mechanism of EV dye, as model compound of triphenylmethane dye, with active Zn metal, by HPLC-ESI-MS and GC-MS.

Conclusions: $\mathrm{ZnO}$ nanostructure/Zn-foils had an excellent potential for future applications on the photocatalytic degradation of the organic dye in the environmental remediation. The intermediates of the degradation process were separated and characterized by the HPLC-PDA-ESI-MS and GC-MS, and twenty-six intermediates were characterized in this study. Based on the variation of the amount of intermediates, possible degradation pathways for the decolorization of dyes are also proposed and discussed.
\end{abstract}

Keywords: HPLC-PDA-ESI-MS, GC-MS, EV dye, Zinc foil, Degradation mechanism

\section{Background}

It is estimated that over 700,000 tons of dyes and pigments are produced annually worldwide, $20 \%$ of which are utilized for textile dyeing and finishing processes [1]. Many of these synthetic dyestuffs cannot be removed using conventional treatments due to their complex polyaromatic structures, resulting in various environmental problems [2]. The textile, paper, food, cosmetic, and leather goods industries are all major consumers of triphenylmethane dyes [1,2]. Previous reports [3,4] have

\footnotetext{
* Correspondence: ccchen@mail.ntcu.edu.tw

${ }^{\dagger}$ Equal contributors

'Department of Science Application and Dissemination, National Taichung University of Education, Taichung 403, Taiwan, Republic of China Full list of author information is available at the end of the article
}

demonstrated the photodegradation of triphenylmethane dyes containing $N$-alkylamine groups via consecutive $\mathrm{N}$ de-alkylation reactions. Other studies have reported that thyroid peroxidase-catalyzed oxidation of triphenylmethane dyes could result in the formation of various $\mathrm{N}$ de-alkylated primary and secondary aromatic amines, with structures similar to those of aromatic amine carcinogens [5]. Previous studies [6,7] on the photocatalytic degradation of nitrogen-containing aromatic compounds have demonstrated that both electrons and hydroxyl radicals transform amine functional groups.

Zinc oxide is an important solid state material possessing photocatalytic [3] and piezoelectric properties, as well as demonstrating field emission and lasing action with a wide range of potential technological applications

\section{(Chemistry Central}


$[8,9]$. Recently, a variety of methods have been developed for the synthesis of nanostructural $\mathrm{ZnO}$, including hydrothermal, vapor-liquid-solid, vapor solid, and other solution processes [10-21]. A low-temperature chemicalliquid deposition method has been employed to grow oriented $\mathrm{ZnO}$ nanorods by continuously supplying $\mathrm{Zn}$ ions from a $\mathrm{Zn}$ foil to form a $\mathrm{ZnO}$ thin film in aqueous formaldehyde solution [22]. Similar reactions have been achieved using $\mathrm{Zn}^{2+}$ salt with ethanol in the presence of amine to produce one-dimensional nanostructures of $\mathrm{ZnO}$ [23]. Hydrothermal reactions have also been used in the preparation of the $\mathrm{ZnO}$ nanorods, employing zinc acetate dissolved in ethanol with polyvinylpyrolidone and $\mathrm{NaOH}$ [24]. Heating zinc nitrate and $\mathrm{NaOH}$ in a mixture of ethylenediamine and water at $180^{\circ} \mathrm{C}$ for $20 \mathrm{~h}$ produces $\mathrm{ZnO}$ nanorods [25]. In the presence of ethylenediamine, the reaction of $\mathrm{Zn}$ foil with water under hydrothermal conditions $\left(150-230^{\circ} \mathrm{C}\right)$ has reportedly yielded $\mathrm{ZnO}$ nanorods [26-31].

It has recently been discovered that cleaving a C-O single bond of the aliphatic alcohols on zinc metal surfaces produces $\mathrm{ZnO}$ nanoparticles [32]. Unfortunately, these techniques often require high temperatures. In addition, the reaction of $\mathrm{Zn}$ metal with liquid water may also produce $\mathrm{ZnO}$ nanostructures in a reaction associated with the evolution of hydrogen in acidic conditions [33]. The methods described in the literature generally use amines and other additives or zinc compounds at higher temperatures.

This study selected zinc foil obtained from waste Alkaline-manganese Dioxide-zinc cells as the substrate for the generation of $\mathrm{ZnO}$ nanostructures because the lattice matching between $\mathrm{ZnO}$ and $\mathrm{Zn}$ crystals facilitates the generation of $\mathrm{ZnO}$ nanostructures, and the zinc foil in these cells is waste material useful in the treatment of organic wastewater through photocatalysis. Zinc foil can serve as both reactant and substrate to support $\mathrm{ZnO}$ nanostructures without an additional substrate. The method is simple and practical, requiring only zinc foil, and may be performed at low temperatures. This simple method has not been previously reported in any studies. This makes it a suitable and economical approach to the treatment of organic wastewater. This study reports on the fabrication of $\mathrm{ZnO}$ nanostructures on zinc foil using a simple solution-based corrosion strategy, and provides detailed descriptions related to the synthesis, characterization, application, and implications of using $\mathrm{Zn}$ in this manner. Other objectives of this research include the identification of reaction intermediates to understand the underlying mechanisms in the degradation of EV dye as a model compound of triphenylmethane dye, with active $\mathrm{Zn}$ metal, using HPLC-ESI-MS and GC-MS. It is hoped that the results will provide a foundation for future environmental applications.

\section{Experimental}

\section{Materials and reagents}

$\mathrm{Zn}$ foils with $99.9 \%$ purity were $0.15 \mathrm{~m}$ in length, $0.15 \mathrm{~m}$ in width, and $2.5 \times 10^{-4} \mathrm{~m}$ in thickness. Alkaline-Manganese Dioxide-Zinc cells was obtained from Eveready, Toshiba, and Panasonic. Ethyl violet dye was obtained from Tokyo Kasei Kogyo Co. The chemical structure of EV is shown in Figure 1. 4-Aminophenol (AP; analytical standard) was purchased from Riedel-deHaen. Reagent-grade ammonium acetate, nitric acid, sodium hydroxide, hydrogen chloride, and HPLC-grade methanol and acetone were purchased from Merck. All of the above agents were used as received without further purification.

\section{Degradation experiments}

The $\mathrm{Zn}$ foils were ultrasonically washed in HPLC-grade acetone three times prior to use. A mixture solution was prepared by adding $\mathrm{Zn}$ foil $(0.05 \mathrm{~m} \times 0.05 \mathrm{~m})$ to a $0.25 \mathrm{~L}$ aqueous solution containing EV at appropriate concentrations. The initial $\mathrm{pH}$ of the solution was adjusted by adding either $\mathrm{NaOH}$ or $\mathrm{HNO}_{3}$ solution to produce reactions of various $\mathrm{pH}$ values. At set intervals during the reaction, the solution was sampled. The residual dye and organic intermediates were analyzed using HPLC-PDAESI-MS and GC-MS. Dark experiments performed in a beaker with $\mathrm{Zn}$ foil also demonstrated the decolorization of the dye solution. Irradiation experiments were carried out for comparison using $15 \mathrm{~W}$ lamps to determine the stability of EV dye under UV or visible light irradiation. The $0.01 \mathrm{gL}^{-1}$ EV solutions did not show significant decoloration under UV irradiation without Zn foil. Following the reaction, the $\mathrm{Zn}$ foil was removed, washed with de-ionized water and ethanol several times, and then

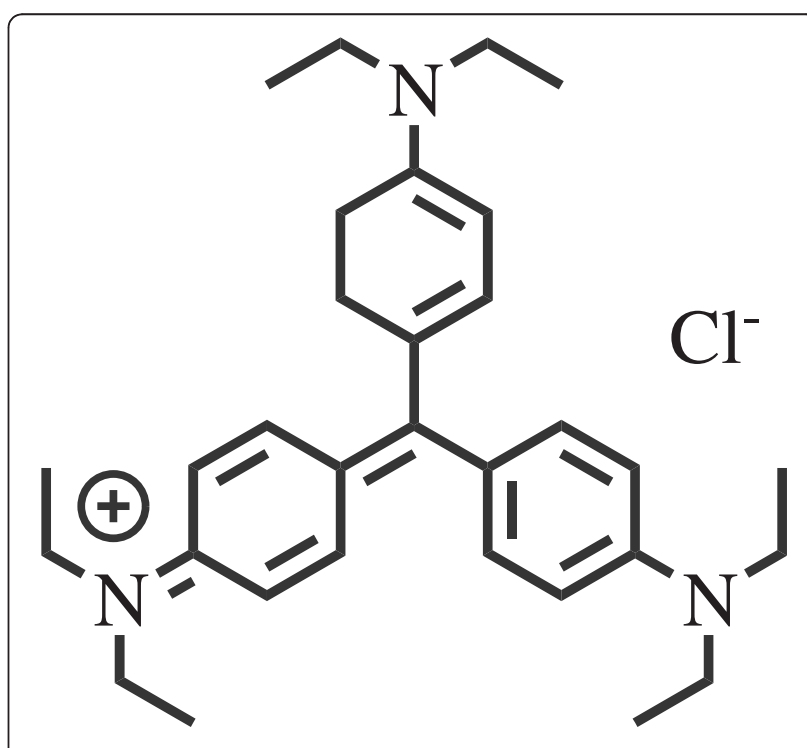

Figure 1 Chemical structure of EV. 
dried with nitrogen. These $\mathrm{Zn}$ foils were characterized using X-ray diffraction (XRD), field emission scanning electron microscopy (FE-SEM), and high resolution $\mathrm{X}$-ray photoelectron spectrometry (HRXPS).

\section{Instruments and analytical methods}

XRD patterns were recorded on a MAC Science, MXP18 X-ray diffractometer with $\mathrm{Cu} \alpha$ radiation, operating at $40 \mathrm{kV}$ and $0.08 \mathrm{~A}$. FE-SEM measurement was carried out using a field-emission microscope (JEOL JSM-7401 F) operating at an acceleration voltage of $1.5 \times 10^{4} \mathrm{~V}$. HRXPS measurement was carried out with ULVAC-PHI XPS: PHI Quantera SXM to measure changes in the surface structure following reflux treatment. The binding energy values reported in the present work were corrected with a C1s peak at $284.8 \mathrm{eV}$ to take into account charging effects.

A Waters ZQ LC/MS system equipped with Waters 1525 Binary HPLC pumps, a Waters 2998 Photodiode Array Detector, a Waters 717 plus auto sampler, and a Waters micromass-ZQ 2000 detector were used. The analysis of organic intermediates was accomplished using HPLC-PDA-ESI-MS following the readjustment of chromatographic conditions to make the mobile phase compatible with the working conditions of the mass spectrometer. Two types of eluent were employed in this study: solvent $\mathrm{A}, 0.025 \mathrm{M}$ aqueous ammonium acetate buffer ( $\mathrm{pH}$ 6.9); and solvent $\mathrm{B}$, methanol. LC was carried out on an Atlantis ${ }^{\mathrm{TM}} \mathrm{dC} 18$ column $(0.25 \mathrm{~m} \times 0.046 \mathrm{~m}$ i. d., $5 \times 10^{-6} \mathrm{~m}$ film thickness). The flow rate of the mobile phase was set at $0.001 \mathrm{~L} \cdot \mathrm{min}^{-1}$. Column effluent was introduced into the ESI source of the mass spectrometer.

Solid-Phase extraction (SPE) was employed for the preconcentration of irradiated samples prior to GC-MS analysis. GC/MS analysis was performed on a Perkin-Elmer AutoSystem-XL gas chromatograph interfaced with a TurboMass selective mass detector. Separation was carried out in a DB-5 capillary column (5\% diphenyl/95\% dimethylsiloxane) with $60 \mathrm{~m}, 2.5 \times 10^{-4} \mathrm{~m}$ i.d., and film thickness of $1.0 \times 10^{-6} \mathrm{~m}$. Electron impact (EI) mass spectra were monitored from 35 to $300 \mathrm{~m} / \mathrm{z}$. The ion source and inlet line temperatures were set at 220 and $280^{\circ} \mathrm{C}$, respectively.

\section{Results and discussion FE-SEM-EDS}

Figures 2 and 3 show SEM images of the microcrystalline $\mathrm{ZnO}$ nanostructures generated on the surface of the $\mathrm{Zn}$ foil. The diameter of $\mathrm{ZnO}$ formations increased with reaction time. Figure 2 shows a top-down image of rods (polycrystallines) approximately $0.2-1 \times 10^{-7} \mathrm{~m}$ in diameter and $1.5-3 \times 10^{-7} \mathrm{~m}$ in length with microcrystalline structures approximately $3-5 \times 10^{-6} \mathrm{~m}$ in diameter. The composition of the rods was characterized using energy dispersive spectroscopy (EDS), which revealed $\mathrm{Zn}$ and $\mathrm{O}$ as the only elementary components with an oxygen deficiency ( $\mathrm{Zn}: \mathrm{O} \sim 2: 1$ atomic ratio) [34]. Figure 3 shows the growth of $\mathrm{ZnO}$ film on a variety of $\mathrm{Zn}$ foils.

\section{XRD}

Figure 4 shows the XRD pattern of $\mathrm{ZnO}$ samples prepared in DI water at room temperature without/with irradiation. All absorption peaks corresponded well with $\mathrm{ZnO}$ (JCPDS card No. 36-1451) and Zn (JCPDS card No. 4-831). No obvious diffraction patterns were observed for impurities. The characteristic diffraction pattern of $\mathrm{ZnO}\left(\begin{array}{lll}1 & 0 & 0\end{array}\right),\left(\begin{array}{lll}0 & 0 & 2\end{array}\right)$, and (1 01 ), together with the diffraction pattern of $\mathrm{Zn}$ ( $\left.\begin{array}{lll}0 & 0\end{array}\right),\left(\begin{array}{lll}1 & 0 & 0\end{array}\right)$, and ( $\left(\begin{array}{lll}1 & 0 & 1\end{array}\right)$ appeared in all samples.

\section{XPS}

Figure 5 shows the XPS spectra of the $\mathrm{ZnO}$ samples obtained under various conditions. The binding energies of O1s in all samples were within 529.1-531.1 eV, which further confirmed the presence of $\mathrm{Zn}^{2+}$ and $\mathrm{O}^{2-}$ in all samples.

From the results of analysis, the natural oxidation of zinc metal by oxygen dissolved in water is rather slow due to the surface oxide layer at room temperature. However, with dye solutions, this spontaneous oxidation reaction can be drastically accelerated, enabling the rapid generation of $\mathrm{ZnO}$ nano-clusters on the surface of the zinc foil. The reaction between $\mathrm{Zn}$ and $\mathrm{O}_{2}$ in an aqueous solution is generally recognized to produce $\mathrm{ZnO}$, as shown in Equations (1, 2, 3 and 4).

$$
\begin{aligned}
& \mathrm{Zn} \rightarrow \mathrm{Zn}^{2+}+2 \mathrm{e}^{-} \mathrm{E}^{\circ}=0.76 \mathrm{~V} \\
& 1 / 2 \mathrm{O}_{2}+\mathrm{H}_{2} \mathrm{O}+2 \mathrm{e}^{-} \rightarrow 2 \mathrm{OH}^{-} \quad \mathrm{E}^{\circ}=0.80 \mathrm{~V} \\
& \mathrm{Zn}^{2+}+2 \mathrm{OH}^{-} \rightarrow \mathrm{ZnO}+\mathrm{H}_{2} \mathrm{O} \mathrm{E}^{\circ}=0.49 \mathrm{~V} \\
& \mathrm{Zn}+1 / 2 \mathrm{O}_{2} \rightarrow \mathrm{ZnO} \mathrm{E}^{\circ}=2.05 \mathrm{~V}
\end{aligned}
$$

The results obtained by reacting $\mathrm{Zn}$ metal with water are encouraging and have led to an examination of the reaction of ethyl violet dye in aqueous solutions. This study describes a very simple method to generate $\mathrm{ZnO}$ nanostructures in which ethyl violet dye is decomposed through a reaction of liquid water with metals. Similar reaction of $\mathrm{Zn}$ metal with liquid water may also produce $\mathrm{ZnO}$ nanostructures in a reaction associated with the evolution of hydrogen in acidic conditions. The methods described in the literature generally use amines and other additives or zinc compounds at higher temperatures [33].

\section{Photoirradiation experiments}

Figure 6 presents typical kinetic data illustrating the effects of photo-irradiation. The experiment with $\mathrm{Zn}$ in 


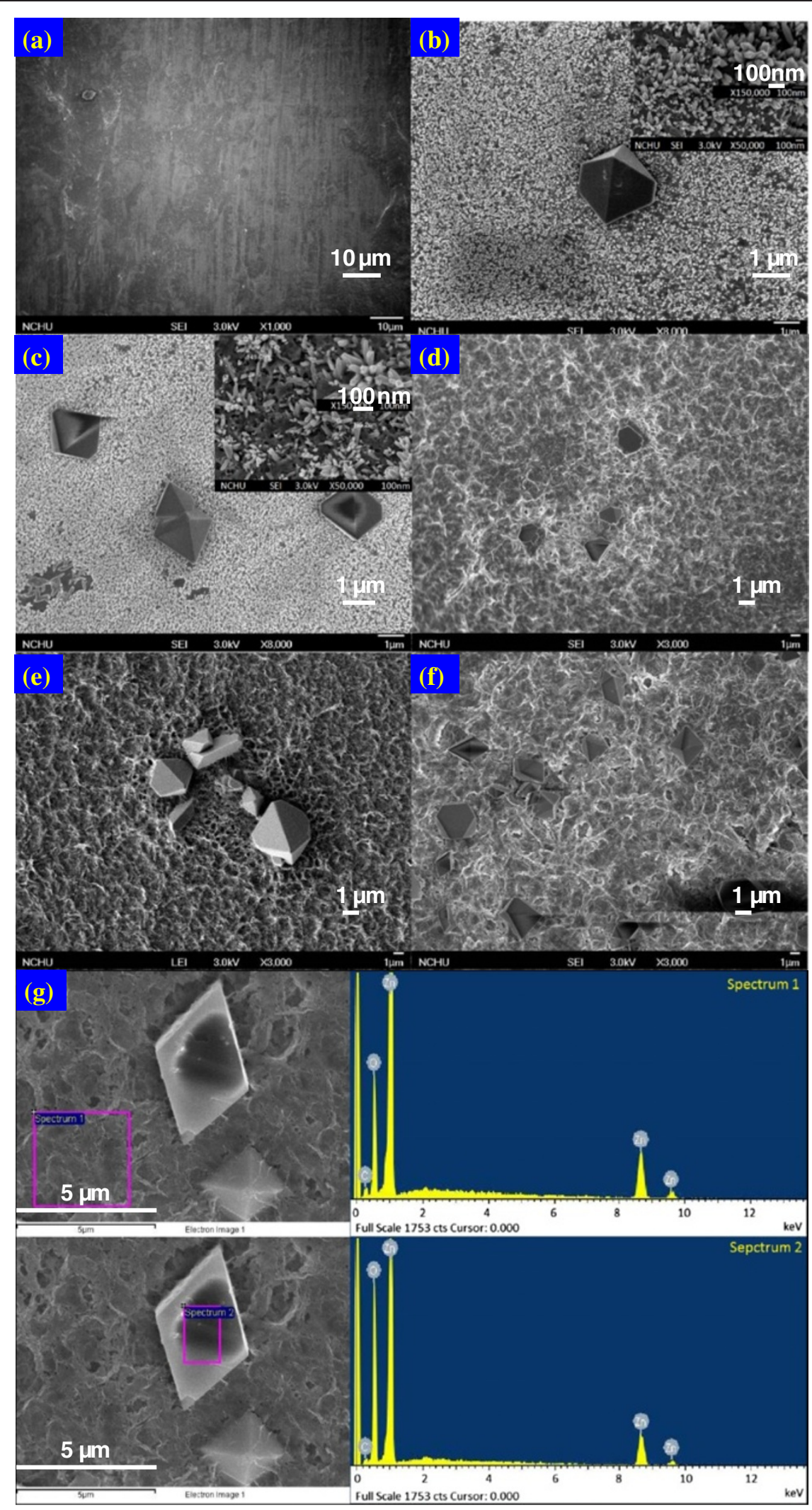

Figure 2 FE-SEM images of Zn foil in DI water at room temperature for (a) 0 h, (b) 8 h, (c) 16 h, (d) 24 h, (e) 32 h, (f) 40 h. Inset images are enlarged images for clarity. (g) Showed the EDX of various spot of the Zn surface after $24 \mathrm{~h}$ DI water exposure. 


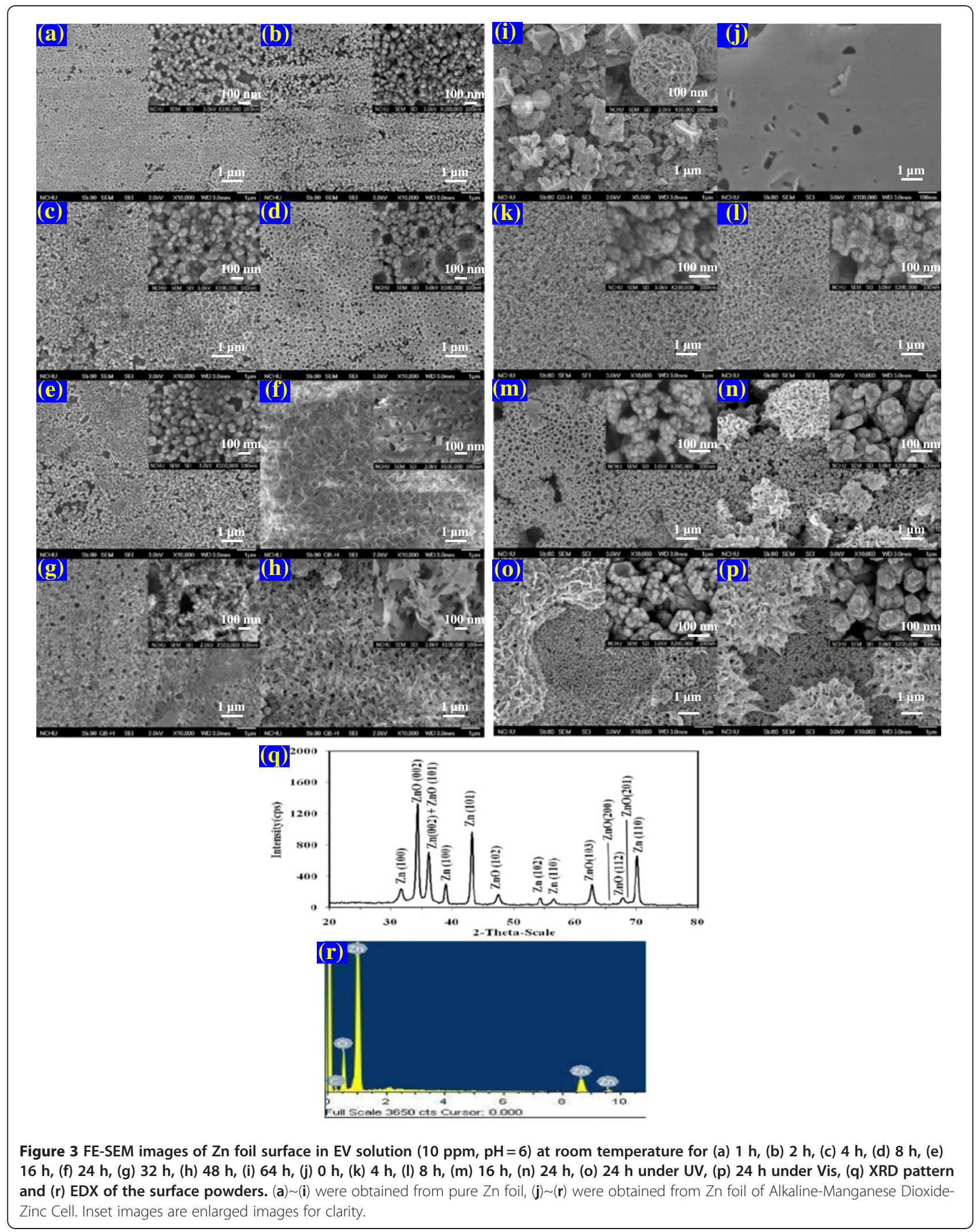




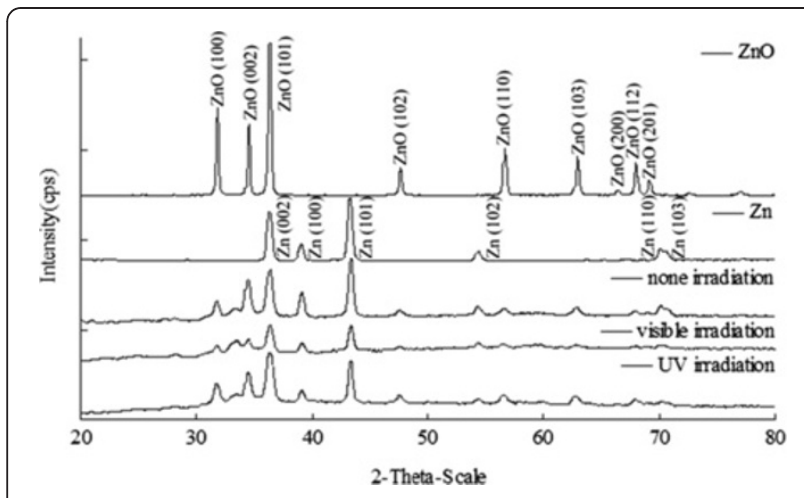

Figure 4 The XRD patterns of $\mathrm{ZnO} / \mathrm{Zn}$ film in DI water under UV and visible irradiation for $64 \mathrm{~h}$.

completely dark conditions shows that approximately $80 \%$ of the EV dye on the Zn surface had degraded after $8 \mathrm{hr}$. The results of the photo-irradiation experiments demonstrate that under visible light conditions, the EV concentration decreased by $93 \%$ after $8 \mathrm{hr}$ of irradiation, while nearly $96 \%$ of the EV was removed after $8 \mathrm{hr}$ of UV irradiation. The reaction rates of EV dye degradation on $\mathrm{P} 25-\mathrm{TiO}_{2}$ have been prepared to compare with those on $\mathrm{ZnO} / \mathrm{Zn}$ system without or with UV or visible light irradiation under identical condition (Figure 6). As a comparsion, $\mathrm{P}-25 \mathrm{TiO}_{2}$ was also performed under identical conditions. All the degradation of $\mathrm{EV}$ on $\mathrm{ZnO}$ or $\mathrm{ZnO} / \mathrm{Zn}$ was significantly higher than that on the photocatalyst P25. As indicated by the SEM and the XRD, in the dark controlled experiments, the EV dye may have been degraded by $\mathrm{Zn}$ in a reduction reaction resulting in the production of $\mathrm{ZnO}$, which enhanced the photocatalytic reaction under photoirradiation reaction conditions. $\mathrm{ZnO}$-assisted photocatalytic degradation of the triphenylmethane dye under UV-365 nm and visible light irradiation was reported [3,25]. This study clearly reveals that both $\mathrm{Zn}$ and $\mathrm{ZnO}$ are capable of degrading EV dye, the efficiency of which is primarily provided by

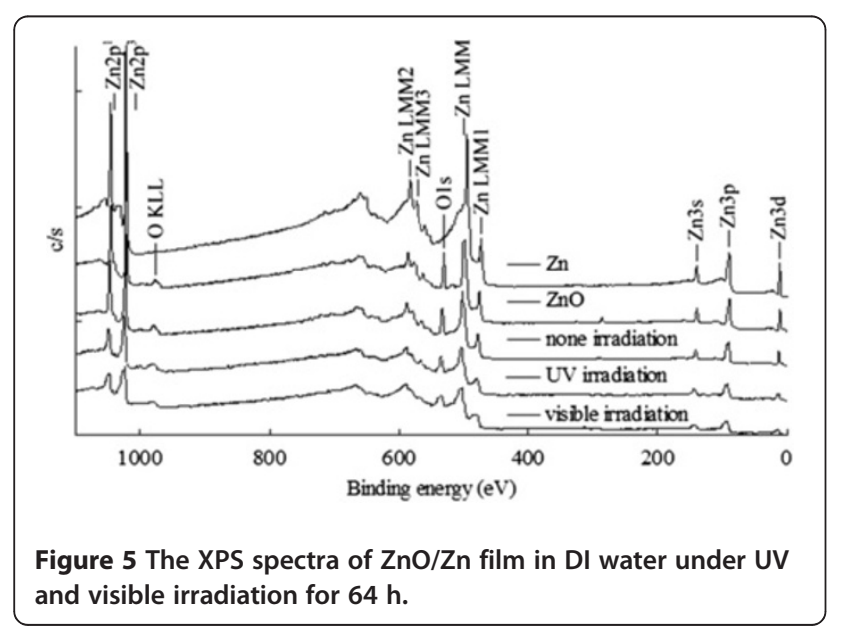

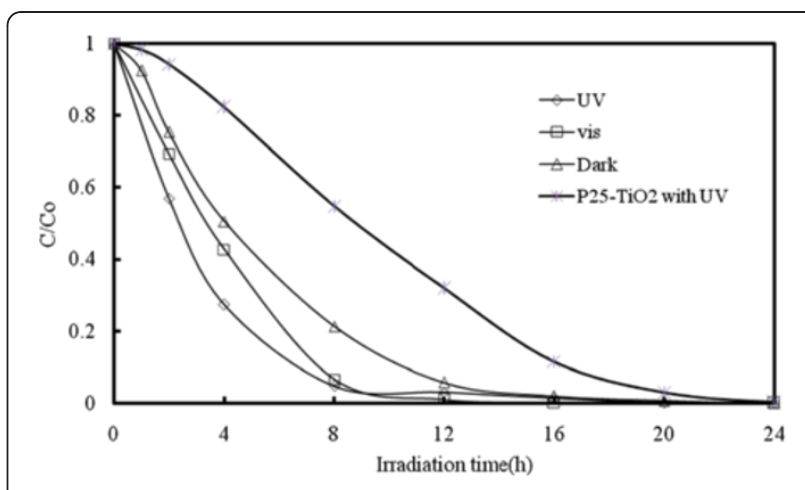

Figure 6 The direct degradation of EV at dark and different wavelength irradiation: $365 \mathrm{~nm}$ and visible light. ( $E V=10 \mathrm{ppm}$, $\mathrm{pH}=6, \mathrm{Zn}$ foil $=5 \times 5 \mathrm{~cm}^{2}$ ).

the reduction of $\mathrm{Zn}$; however, under photo-irradiation conditions, the $\mathrm{ZnO}$ acts as a photocatalyst, which also makes a significant contribution to the degradation of EV.

\section{Effect of $\mathrm{pH}$ and dye concentration}

The degradation rate of the EV dye as a function of reaction $\mathrm{pH}$ is shown in Figure 7. The degradation rate of the EV dye remained relatively constant as the $\mathrm{pH}$ of the solution was increased. A reduction in the degradation rate was clearly observed at $\mathrm{pH} 3$, and might be attributable to the reaction of zinc metal with protons, and the subsequent slow release of hydrogen gas. It has been reported that the $\mathrm{Zn}$ metal in acidic water might result in the formation of $\mathrm{ZnO}$ film associated with the evolution of hydrogen [31]. In typical textile effluent, dye concentrations range from 150 to $200 \mathrm{ppm}$. By varying the initial dye concentrations from 10 to $200 \mathrm{ppm}$ at constant $\mathrm{Zn}$-foil loading $(\mathrm{pH}=6)$, we determined the effect of dye concentration on the degradation rate, the results of which are shown in Additional file 1: Figure S1. Degradation efficiency is inversely influenced by the

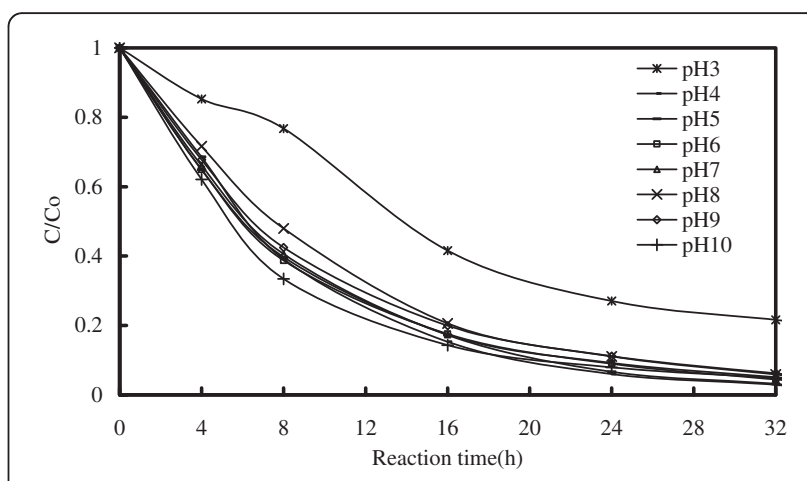

Figure $7 \mathrm{pH}$ effect on the EV degradation rate: $\mathrm{Zn}$ foil of Alkaline-Manganese Dioxide-Zinc Cell; EV = 10 ppm; without UV irradiation. 


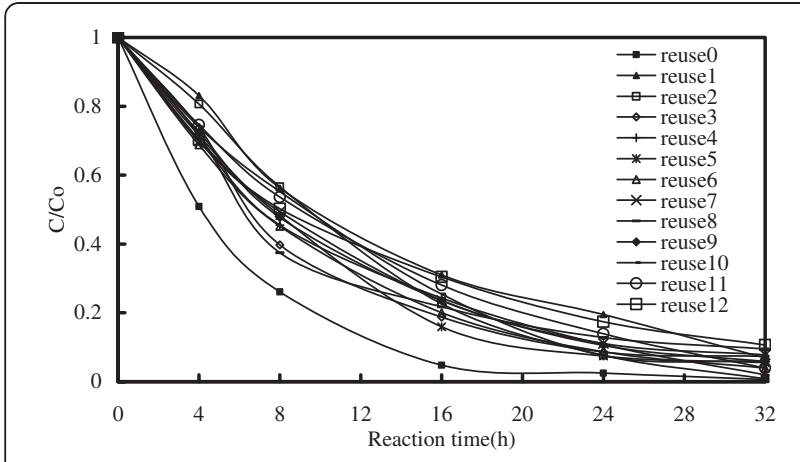

Figure 8 Comparison of degradation rate for the degradation of EV under $\mathrm{Zn}$ foil of Alkaline-Manganese Dioxide-Zinc Cell and reused $\mathrm{Zn}$ foil $(10 \mathrm{ppm}, \mathrm{pH}=6)$.
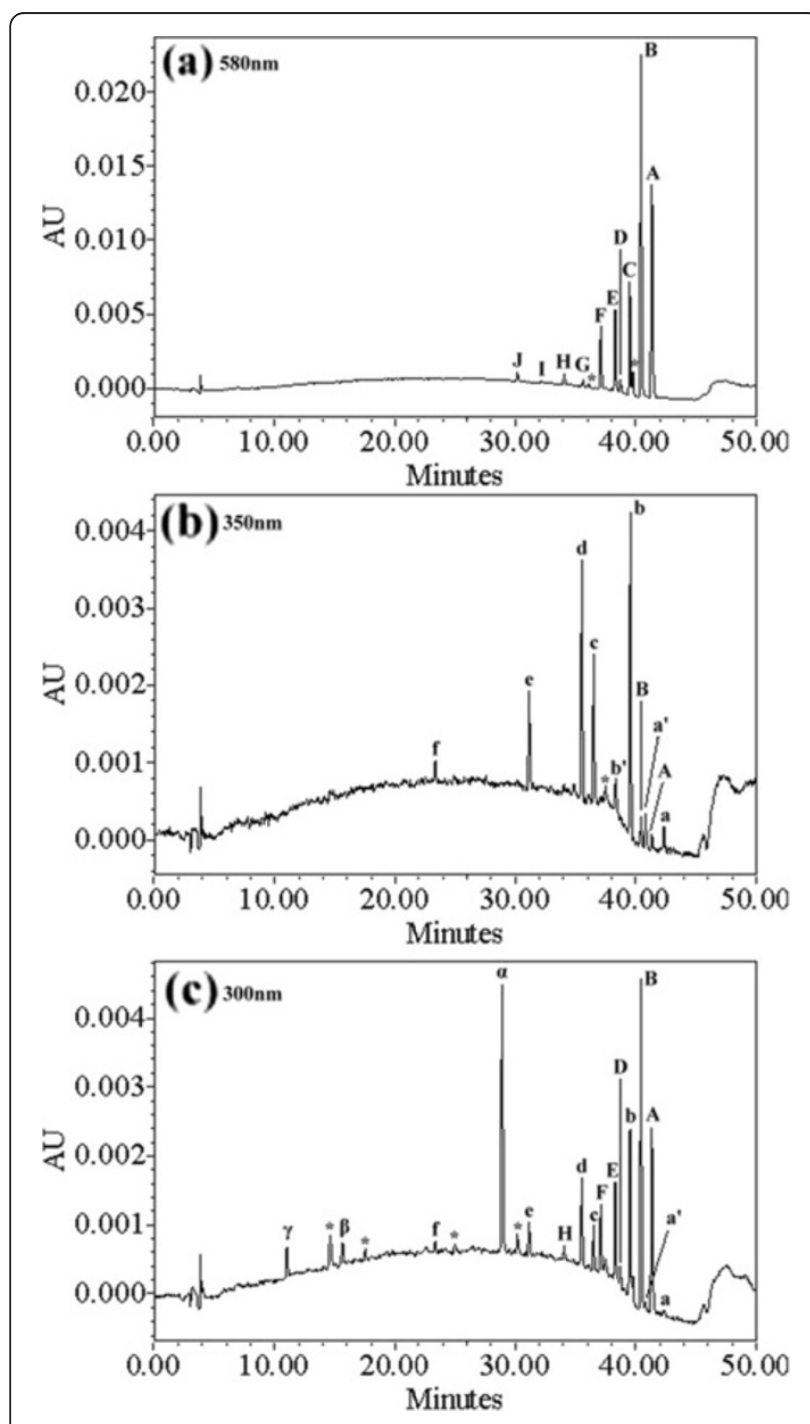

Figure 9 HPLC chromatogram of intermediates at pH 6 (EV, $\left.0.01 \mathrm{gL}^{-1}\right), 36 \mathrm{~h}$ of reaction with $\mathrm{Zn}$-foil, recorded at (a) $580 \mathrm{~nm}$, (b) $350 \mathrm{~nm}$, and (c) $300 \mathrm{~nm}$, impurities were marked with star.

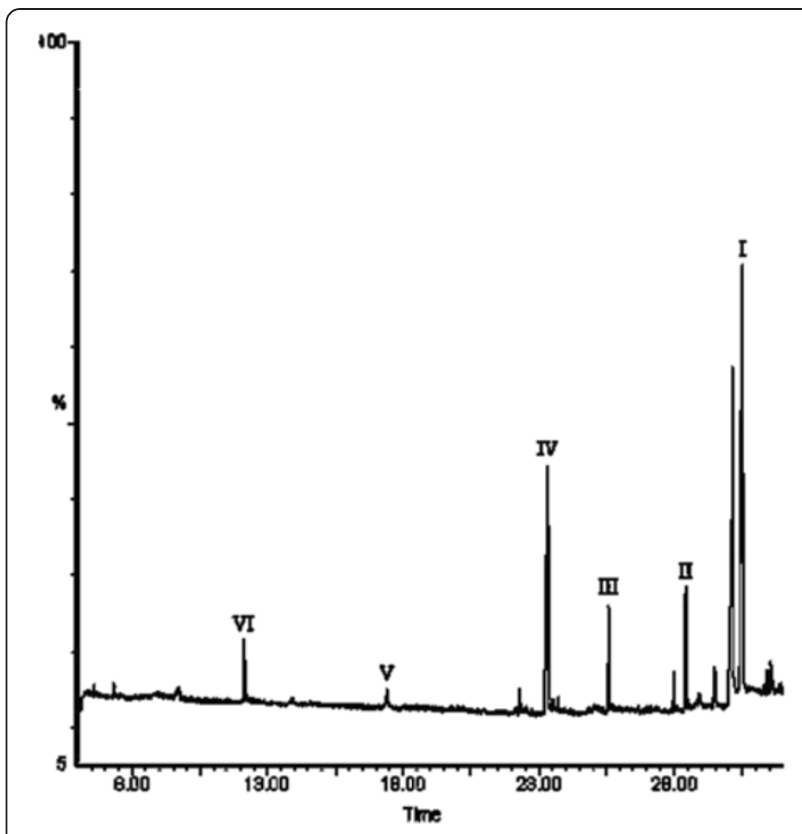

Figure $10 \mathrm{GC}-\mathrm{MS} / \mathrm{El}$ chromatogram obtained for a SPE extract of solution after $36 \mathrm{~h}$ of EV dye with $\mathrm{Zn}$-foil under dark condition.

concentration of the dye, which can be explained by the fact that as the concentration of the dye increased, the equilibrium adsorption time of dye on the $\mathrm{Zn}$-foil surface active sites increased. Thus, the competitive adsorption of $\mathrm{O}_{2}$ on the same sites decreased, resulting in a reduced $\mathrm{ZnO}$ formation rate and lower $\mathrm{EV}$ dye degradation efficiency.

\section{Reusability of Zn-foil}

This experiment involved a comparison of degradation efficiency resulting from the use of freshly prepared $\mathrm{Zn}$ foil compared with that of reused $\mathrm{Zn}$-foil under the same processing conditions. As shown in Figure 8, reused $\mathrm{Zn}$-foil exhibited lower degradation efficiency than fresh $\mathrm{Zn}$-foil, which could be attributed to a reduction in the number of active sites on the surface of the reused $\mathrm{Zn}$-foil. As indicated in Figure 8, degradation efficiency is unaffected by the duration of reactions using reused $\mathrm{Zn}$-foil. This can be explained by the fact that the $\mathrm{ZnO}$ is continuously formed and peels off from the $\mathrm{Zn}$-foil surface leaving $\mathrm{ZnO}$ powders following the reaction, as depicted in the SEM images in Figure 3 showing irradiation times ranging from $8 \mathrm{hr}$ to $64 \mathrm{hr}$.

\section{Separation of the intermediates}

Chromatograms recorded at 580, 350, $300 \mathrm{~nm}$ are illustrated in Figure 9. With an increase in UV irradiation time to $36 \mathrm{hr}$ at $\mathrm{pH} \mathrm{6,} \mathrm{twenty-one} \mathrm{components} \mathrm{were} \mathrm{identified}$ 
within a $50 \mathrm{~min}$ retention time. The EV dye and its related intermediates were denoted as species A-J, a-f, a'- $\mathrm{b}^{\prime}$, and $\alpha-\gamma$. Except for the initial EV dye (peak A), the peaks initially increased before subsequently decreasing, indicating the formation and the transformation of intermediates. Figure 10 shows the GC chromatogram obtained from an SPME extract of EV solution after $36 \mathrm{hr}$ of photoirradiation reaction. Six compounds were detected as possible degradation intermediates. These intermediates were denoted as compounds I-VI.

\section{UV-visible spectra of the intermediates}

The UV-PDA adsorption spectra of the intermediates are depicted in the Additional file 1: Figure S2, identified as A-J and a-f, corresponding to the peaks A-J and a-f, in Figure 9, respectively. The maximum absorption of the spectral band shifted from $591.8 \mathrm{~nm}$ (spectrum A) to $561.7 \mathrm{~nm}$ (spectrum I), and from $371.6 \mathrm{~nm}$ (spectrum a) to $340.6 \mathrm{~nm}$ (spectrum f). Presumably, these shifts are due to the formation of a series of $N$-de-ethylated and $\mathrm{N}$-hydroxyethylated intermediates. From these results, several groups of intermediates were identified.

The first group is marked in the chromatogram and illustrated in Figure 9(a). The major absorption bands of the intermediates of $N$-de-ethylated $\mathrm{EV}$ dye are shifted toward the blue region, $\lambda_{\max }$, A (EV), $591.8 \mathrm{~nm}$; B, $585.6 \mathrm{~nm}$; C, $571.9 \mathrm{~nm}$; D, $573.2 \mathrm{~nm}$; E, $582.1 \mathrm{~nm}$; F, $569.7 \mathrm{~nm}$; G, $565.6 \mathrm{~nm}$; H, $563.6 \mathrm{~nm}$; I, $561.7 \mathrm{~nm}$. The $\mathrm{N}$-de-ethylation of the EV dye causes the shift in wavelength because of an attack on the $N, N$-diethyl or $N$-ethyl group by the active oxygen species, as depicted in Additional file 1: Figure S2. It has been reported [35] that EV dye is $N$-de-ethylated in a stepwise manner (i.e., Ethyl groups are removed stepwise as confirmed by the blue shifts in the maximum absorbance of the separated intermediates).

Table 1 Intermediates of the degradation of EV identified by HPLC-ESI-MS or GC-EI-MS

\begin{tabular}{|c|c|c|c|c|}
\hline HPLCpeaks & Intermediates & Abbreviation & MS peaks $(\mathrm{m} / \mathrm{z})$ & Absorption maximum (nm) \\
\hline A & $N, N, N^{\prime}, N^{\prime}, N^{\prime \prime}, N^{\prime \prime}$-hexaethylpararosaniline & EV & 456.49 & 591.8 \\
\hline B & $N, N$-diethyl- $N^{\prime}, N^{\prime}$-diethyl-N"-ethylpararosaniline & DDEPR & 428.88 & 585.6 \\
\hline C & $N, N$-diethyl- $N^{\prime}$-ethyl- $N "$-ethylpararosaniline & DEEPR & 400.21 & 571.9 \\
\hline D & $N, N$-diethyl- $N^{\prime}, N^{\prime}$-diethylpararosaniline & DDPR & 400.19 & 573.2 \\
\hline $\mathbf{E}$ & $N$-ethyl-N'-ethyl-N"-ethyl pararosaniline & EEEPR & 372.16 & 582.1 \\
\hline $\mathbf{F}$ & $N, N$-diethyl- $N^{\prime}$-ethylpararosaniline & DEPR & 372.21 & 569.7 \\
\hline G & $N$-ethy- $N^{\prime}$-ethylpararosaniline & EEPR & 344.19 & 565.6 \\
\hline H & $\mathrm{N}, \mathrm{N}$-diethylpararosaniline & DPR & N/A & 563.6 \\
\hline I & $\mathrm{N}$-ethylpararosaniline & EPR & N/A & 561.7 \\
\hline J & pararosaniline & PR & N/A & N/A \\
\hline $\mathbf{a}$ & 4-(N,N-diethylamino)-4'-(N',N'-diethylamino)benzophenone & DDBP & 325.45 & 371.6 \\
\hline b & 4-(N,N-diethylamino)-4'-( $N^{\prime}$-ethylamino)benzophenone & DEBP & 297.48 & 366.7 \\
\hline c & 4-(N-ethylamino)-4'-(N'-ethylamino)benzophenone & EEBP & 269.31 & 365.5 \\
\hline d & 4-(N,N-diethylamino)-4'-aminobenzophenone & DBP & 269.45 & 367.9 \\
\hline e & 4-(N-ethylamino)-4'-aminobenzophenone & EBP & 241.18 & 352.6 \\
\hline f & 4,4'-bis-aminobenzophenone & $\mathrm{BP}$ & 213.13 & 340.6 \\
\hline $\mathbf{a}^{\prime}$ & 4-(N,N-diethylamino)-4'-( $N^{\prime}$-hydroxyethyl- $N^{\prime}$-ethylamino)benzophenone & DHEBP & 341.23 & 371.6 \\
\hline $\mathbf{b}^{\prime}$ & 4-(N-hydroxyethyl-N-ethylamino)-4'-(N'-ethylamino)benzophenone & HEEBP & 313.08 & 369.1 \\
\hline a & 4-(N,N-diethylamino)phenol & DAP & 166.25 & 290.4 \\
\hline $\boldsymbol{\beta}$ & 4-(N-ethylamino)phenol & EAP & 137.15 & 282.1 \\
\hline $\boldsymbol{v}$ & 4-aminophenol & AP & 109.35 & 272.6 \\
\hline I & N,N-diethylaminobenzene & $\mathrm{DBz}$ & 149 & 310.7 \\
\hline II & N-ethylaminobenzene & $\mathrm{EBz}$ & 121 & 301.5 \\
\hline III & Aminobenzene & $A B z$ & 93 & 282.9 \\
\hline IV & Acetamide & AAm & 59 & N/A \\
\hline $\mathbf{v}$ & 2-Propenoic & PAC & 72 & N/A \\
\hline VI & Acetic & AAC & 60 & N/A \\
\hline
\end{tabular}

Conditions: $\mathrm{Zn}$ foil, $0.01 \mathrm{gL}^{-1} \mathrm{EV}$, reaction $36 \mathrm{~h}$. 


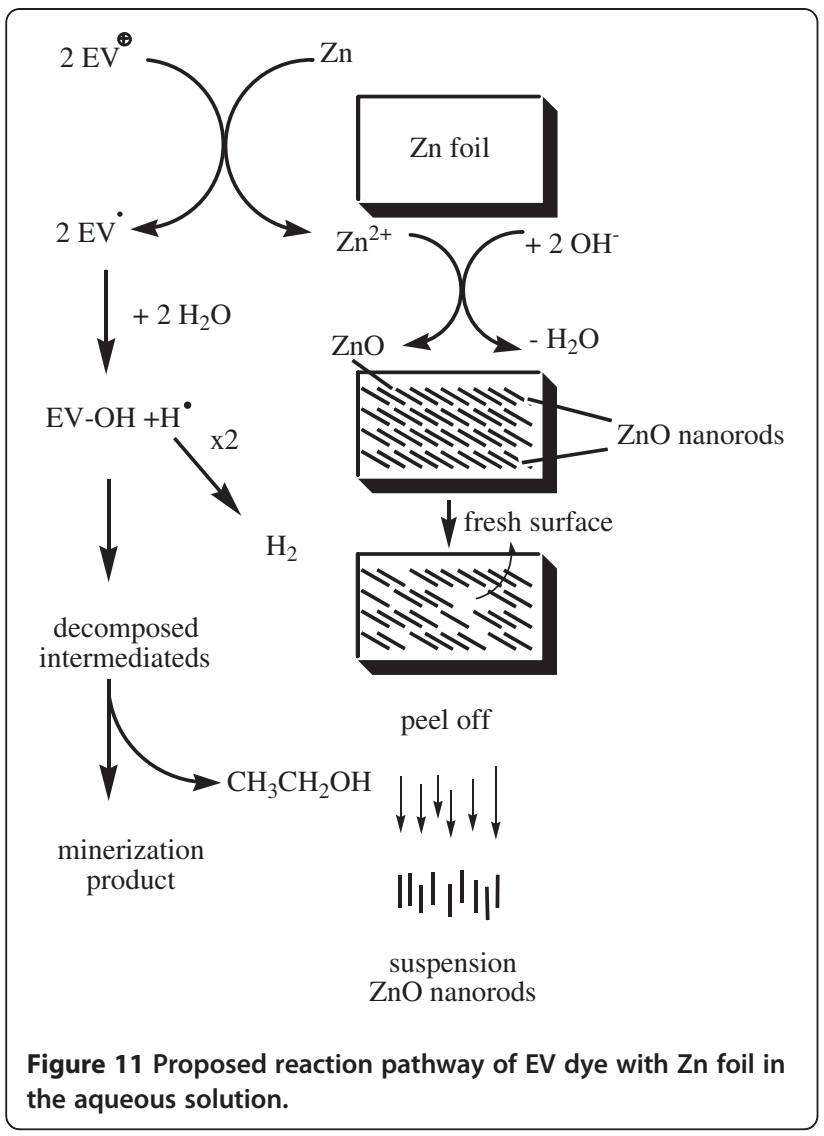

The second and third groups are marked in the chromatogram in Figure 9(b). Destruction of EV yields DAP, DDBP, and $N$-de-ethylated products, $N$-hydroxyethylated intermediates. The $N$-de-ethylation derivatives of the DDBP and the $N$-hydroxyethylated intermediates of the $N$-de-ethylated DDBP species, produced by the cleavage of the EV chromophore ring structure, have their $\lambda_{\max }$ blue shifted: a, $371.6 \mathrm{~nm}$; b, $366.7 \mathrm{~nm}$;, $365.5 \mathrm{~nm}$; $367.9 \mathrm{~nm}$; e, $352.6 \mathrm{~nm}$; f, $340.6 \mathrm{~nm}$. The proposed intermediate a compared well with standard material of $4-(N$, $N$-diethylamino)-4' - ( $N^{\prime}, N^{\prime}$-diethylamino) benzophenone.

The fourth and the fifth groups are marked in the chromatogram and illustrated in Figure 9(c). The $N$-deethylation derivatives of the DAP, produced by the cleavage of the EV chromophore ring structure, also have their $\lambda_{\max }$ blue shifted: $\alpha, 290.4 \mathrm{~nm} ; \beta, 282.1 \mathrm{~nm} ; \gamma$, $272.6 \mathrm{~nm}$ as previously reported [36].

\section{Mass spectra of the intermediates}

Intermediates were further identified using HPLC-ESI mass spectrometry, and the relevant mass spectra are illustrated in the Additional file 1: Figure S3 and further summarized in Table 1. The molecular ion peaks of the intermediates all appeared in protonated form. Results confirm that component A $(\mathrm{m} / \mathrm{z}=456.49)$ is $\mathrm{EV}$. The other components are $\mathrm{B}, \mathrm{m} / \mathrm{z}=428.88 ; \mathrm{C}, \mathrm{m} / \mathrm{z}=400.21$;
$\mathrm{D}, \mathrm{m} / \mathrm{z}=400.19 ; \mathrm{E}, \mathrm{m} / \mathrm{z}=372.16 ; \mathrm{F}, \mathrm{m} / \mathrm{z}=372.21 ; \mathrm{G}, \mathrm{m} /$ $\mathrm{z}=344.19 ; \mathrm{a}, \mathrm{m} / \mathrm{z}=325.45 ; \mathrm{b}, \mathrm{m} / \mathrm{z}=297.48 ; \mathrm{c}, \mathrm{m} / \mathrm{z}=269.31$; d, $\mathrm{m} / \mathrm{z}=269.45 ; \mathrm{e}, \mathrm{m} / \mathrm{z}=241.18 ; \mathrm{f}, \mathrm{m} / \mathrm{z}=213.13 ; \alpha, \mathrm{m} /$ $\mathrm{z}=166.25 ; \quad \beta, \mathrm{m} / \mathrm{z}=137.15 ; \gamma, \mathrm{m} / \mathrm{z}=109.35$. The other intermediates are shown in the GC-MS/EI chromatogram, and the relevant mass spectra are illustrated in the Additional file 1: Figure S4. Table 1 presents the molecular ions of intermediates (I-VI), which characterize its corresponding structure. The peaks eluting at 30.48, 28.49, 25.61, 23.39, 17.57, and $12.38 \mathrm{~min}$ during GC-MS were identified as $\mathrm{N}, \mathrm{N}$-diethylaminobenzene, $\mathrm{N}$-ethylaminobenzene, aminobenzene, acetamide, 2-propenoic acid, and acetic acid, which matched a standard library search with the values of $87 \%, 82 \%, 83 \%, 71 \%, 88 \%$, and $95 \%$, respectively (see Additional file 1: Figure S4). The intermediates identified in the study were also reported in a previous study on the $\mathrm{MEK} / \mathrm{TiO}_{2}$ system [36].

\section{Degradation mechanisms of EV}

Most EV radicals are generated directly from the redox reaction between $\mathrm{Zn}$-foil and surface-adsorbed $\mathrm{EV}$ dye. The attack by $\mathrm{H}_{2} \mathrm{O}$ on the ethyl group of diethylamine resulted in $\mathrm{N}$-de-ethylated intermediate and ethanol. The above results can be seen more clearly in Figure 11. The degradation reactions occurred at the interface between the $\mathrm{Zn}$ metal and liquid water, which resulted in nanostructural $\mathrm{ZnO}$ following the evolution of hydrogen [32]. According to earlier reports [3,6], most $N$-de-alkylation processes are preceded by the formation of a nitrogen-centered radical, while the destruction of dye chromophore structures is preceded by the generation of a carbon-centered radical $[3,4]$. Consistent with this, the degradation of EV must occur via two different photodegradation pathways, namely the destruction of the chromophore structure and $\mathrm{N}$-de-ethylation resulting from the two different radicals, either carbon-centered or nitrogen-centered. Undoubtedly, the electrons from the $\mathrm{Zn}$-foil attack dye molecules, yielding a dye radical. Following this step, the radical Dye undergoes hydrolysis and/or deprotonation, according to the different adsorption modes of EV on the Zn surface. Based on the experimental results mentioned above, we tentatively propose the pathways of degradation depicted in Figure 11.

\section{$\mathrm{N}$-de-ethylation of EV}

$\mathrm{EV}$ receives electrons from the $\mathrm{Zn}$ surface via the positive diethylamine group to form EV radicals and zinc ions. The attack of $\mathrm{H}_{2} \mathrm{O}$ molecules from the ethyl group of diethylamine on the EV radicals resulted in the formation of $\mathrm{N}$-de-ethylated intermediate and ethanol. The mono-de-ethylated dye derivative $\mathrm{B}$ can also be adsorbed onto the $\mathrm{Zn}$ surface, implicating similar events (electron attack, hydrolysis or deprotonation) to yield the bi-deethylated dye derivatives, $\mathrm{C}$ and $\mathrm{D}$. The $\mathrm{N}$-de-ethylation 
process described above continues until the formation of the complete de-ethylated dye J. The concentration of the other intermediates may be too low for detection by HPLC-PDA-ESI-MS. The above results can be seen more clearly in Figure 12.

\section{Destruction of the conjugated structure of the EV}

As described above, electrons flow to the EV molecule via the positive diethylamine group. Following the transfer of electrons, the conjugated structure yields a carbon-centered radical, which is subsequently attacked by molecular oxygen, leading ultimately to a and $\alpha$. The destruction of the conjugated structure of the EV dye most likely occurs through the attack of $\mathrm{O}_{2}$ on the carbon-centered radical of the $\mathrm{EV}$, as intermediates a f are isolated from the HPLC chromatogram. This process also occurs in $\mathrm{N}$-de-ethylated EV derivatives ( $\mathrm{B}$ to $\mathrm{F}$ ), which are adsorbed on the $\mathrm{Zn}$ surface, implicating electrons in other similar events (electron attack, hydrolysis, or deprotonation, and/or oxygen attack) to yield the mono- $\mathrm{N}$-de-ethylated derivative $\mathrm{b}$. A similar process occurred in $\alpha$ to produce $\beta$. The $N$-de-ethylation process for a and $\alpha$ continues until the formation of the

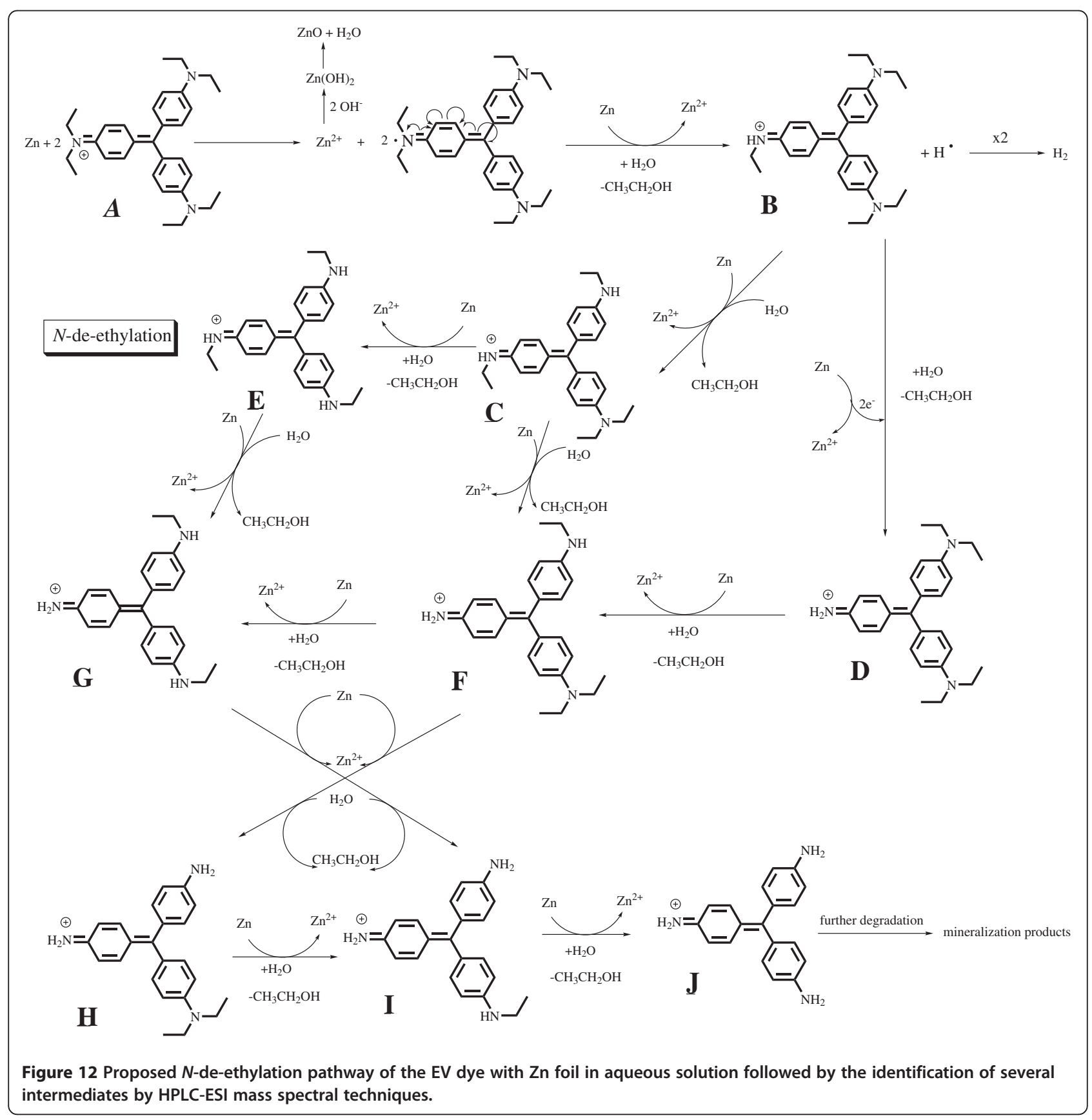




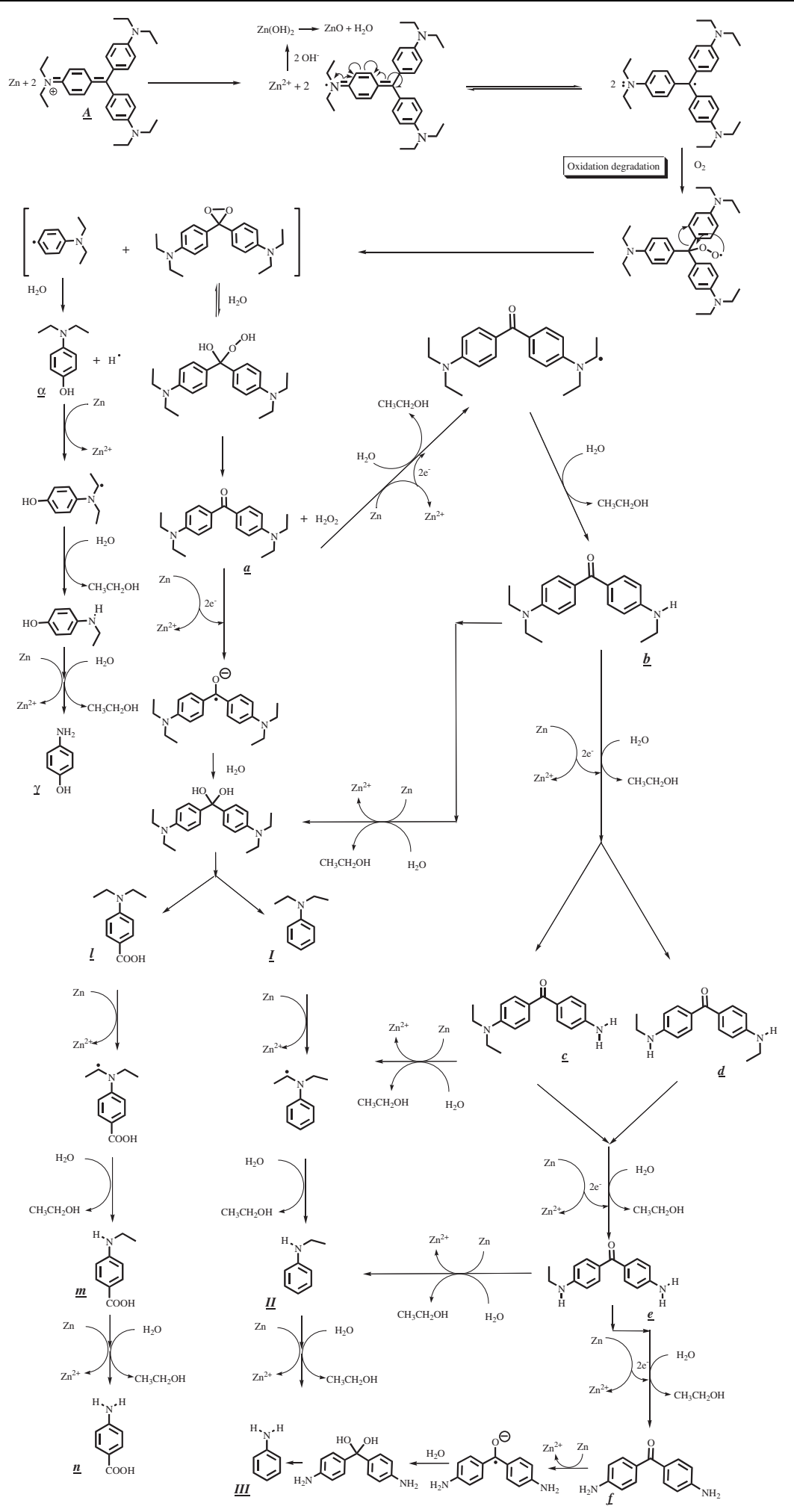

Figure 13 Proposed pathway of the destruction of the conjugated structure of the EV dye with $\mathrm{Zn}$ foil followed by the identification of several intermediates by HPLC-ESI mass spectral techniques. 
complete $N$-de-ethylated derivative $\mathrm{f}$ and $\gamma$. All of the above $\mathrm{N}$-de-ethylation processes also produced a parallel series of $\mathrm{N}$-de-hydroxyethylated intermediates through the hydroxylation of the $N$-ethyl group. All intermediates were further degraded to $\mathrm{N}, \mathrm{N}$-diethylaminobenzene, $\mathrm{N}$-ethylaminobenzene, aminobenzene, acetamide, 2-propenoic acid, and acetic acid, which were subsequently mineralized to $\mathrm{CO}_{3}^{2-}$ and $\mathrm{NO}_{3}^{-}$[35]. The degradation intermediates clearly reached their maximum concentrations, although some might have been under the detection limit. Mechanisms similar to those proposed here were also observed in a previous study of the $\mathrm{MEK} / \mathrm{TiO}_{2}$ system [36].

Further evidence related to the pathway(s) of degradation was obtained by GC-MS spectroscopy. From the results of mass spectral analysis, the major components in the gas chromatogram were identified as $N, N$-diethylaminobenzene, $\mathrm{N}$-ethylaminobenzene, aminobenzene, acetamide, 2-propenoic acid, and acetic acid. The former intermediates (I-III) detected by GC-MS resulted from the cleavage of intermediates in the third group (a-f), leading to aminobenzene derivatives. The latter intermediates (IV-VI) were formed by the cleavage of aromatic derivatives, leading to aliphatic products. The above results can be seen more clearly in Figure 13.

\section{Conclusions}

This paper used HPLC-PDA-ESI-MS analysis to identify the mechanism underlying the degradation of ethyl violet dyes. In this study, a nanostructural $\mathrm{ZnO}$ film was produced on the $\mathrm{Zn}$ foil from Alkaline-Manganese DioxideZinc cells, providing outstanding potential for future applications in the photocatalytic degradation of organic dye for environmental remediation. This study used HPLC-PDA-ESI-MS and GC-MS to differentiate and characterize twenty-six intermediates of the degradation process. According to variations in the quantity of intermediates, various possible degradation pathways for the decolorization of dyes were also proposed and discussed.

\section{Additional file}

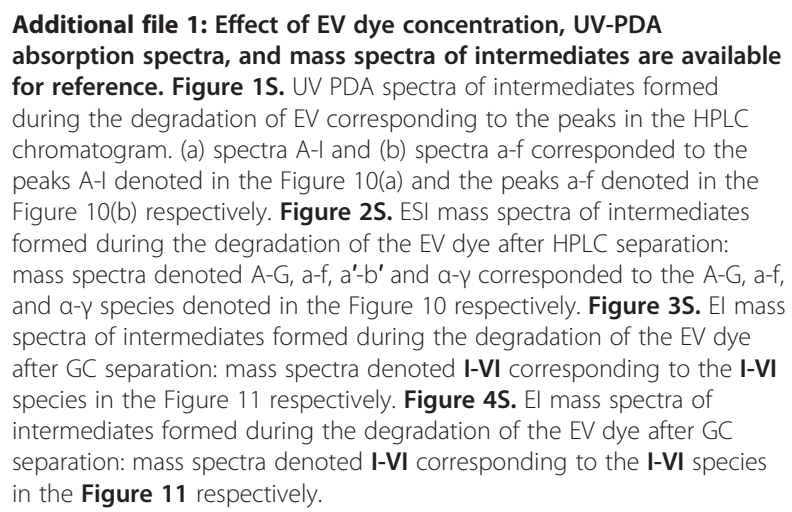

\section{Competing interests}

The author declares that they have no competing interests.

\section{Authors' contributions}

CCC developed the concept, analyzed the data and drafted the manuscript. JXW and WHC carried out the chemical synthesis. WYL and CWW advised on the methods of tests. All authors read and approved the final manuscript.

\section{Acknowledgements}

This research was supported by the National Science Council of the Republic of China (NSC 99-2113-M-142-001-MY2; NSC 100-2622-M-142-001-CC1).

\section{Author details}

'Department of Science Application and Dissemination, National Taichung University of Education, Taichung 403, Taiwan, Republic of China.

${ }^{2}$ Department of Plant Pathology, National Chung Hsing University, Taichung 402Taiwan, Republic of China. ${ }^{3}$ Department of General Education, National Taichung, University of Science and Technology, Taichung 403Taiwan, Republic of China.

Received: 21 February 2012 Accepted: 7 June 2012

Published: 30 June 2012

\section{References}

1. Gessner T, Mayer U: Ullmann's Encyclopedia of Industrial Chemistry. Part A27. Triarylmethane and Diarylmethane Dyes. 6th edition. New York: Wiley-VCH; 2001.

2. Duxbury DF: The photochemistry and photophysics of triphenylmethane dyes in solid and liquid media. Chem Rev 1993, 93:381-433.

3. Chen CC, Fan HJ, Jan JL: Degradation Pathways and Efficiencies of Acid Blue 1 by Photocatalytic Reaction with ZnO Nanopowder. J Phy Chem C 2008, 112:11962-11972.

4. Chen CC, Lu CS: Mechanistic Studies of the Photocatalytic Degradation of Methyl Green: An Investigation of Products of the Decomposition Processes. Environ Sci Technol 2007, 41:4389-4396.

5. Cho BP, Yang T, Blankenship LR, Moody JD, Churchwell M, Beland FA, Culp SJ: Synthesis and characterization of $\mathrm{N}$-demethylated metabolites of malachite green and leucomalachite green. Chem Res Toxicol 2003, 16:285-294.

6. Chen C, Lu C: Photocatalytic Degradation of Basic Violet 4: Degradation Efficiency, Product Distribution, and Mechanisms. J Phy Chem C 2007, 111:13922-13932.

7. Maurino V, Minero C, Pelizzetti E, Piccinini P, Serpone N, Hidaka H: The fate of organic nitrogen under photocatalytic conditions: degradation of nitrophenols and aminophenols on irradiated TiO2. J Photochem Photobiol A Chemistry 1997, 109:171-176.

8. Kong YC, Yu DP, Zhang B, Fang W, Feng SQ: Ultraviolet-emitting ZnO nanowires synthesized by a physical vapor deposition approach. App Phys Lett 2001, 78:407-409.

9. Lyu SC, Zhang Y, Lee CJ, Ruh H, Lee HJ: Low-Temperature Growth of ZnO Nanowire Array by a Simple Physical Vapor-Deposition Method. Chem Mater 2003, 15:3294-3299.

10. Liu Y, Kang ZH, Chen ZH, Shafiq I, Zapien JA, Bello I, Zhang WJ, Lee ST: Synthesis, Characterization, and Photocatalytic Application of Different ZnO Nanostructures in Array Configurations. Cryst Growth Des 2009, 9:3222-3227.

11. Li X, Zhao F, Fu J, Yang X, Wang J, Liang C, Wu M: Double-Sided Comb-Like ZnO Nanostructures and Their Derivative Nanofern Arrays Grown by a Facile Metal Hydrothermal Oxidation Route. Cryst Growth Des 2008, 9:409-413.

12. Greene LE, Law M, Goldberger J, Kim F, Johnson JC, Zhang Y, Saykally RJ, Yang P: Low-Temperature Wafer-Scale Production of ZnO Nanowire Arrays. Angew Chem Int Ed 2003, 42:3031-3034.

13. Li C, Hong G, Wang P, Yu D, Qi L: Wet Chemical Approaches to Patterned Arrays of Well-Aligned ZnO Nanopillars Assisted by Monolayer Colloidal Crystals. Chem Mater 2009, 21:891-897.

14. Huang MH, Mao S, Feick $H$, Yan H, Wu Y, Kind $H$, Weber E, Russo R, Yang $P$. Room-Temperature Ultraviolet Nanowire Nanolasers. Science 2001, 292:1897-1899.

15. Palumbo M, Lutz T, Giusca CE, Shiozawa H, Stolojan V, Cox DC, Wilson RM, Henley SJ, Silva SRP: From Stems (and Stars) to Roses: Shape-Controlled Synthesis of Zinc Oxide Crystals. Cryst Growth Des 2009, 9:3432-3437. 
16. Tak Y, Yong K: Controlled Growth of Well-Aligned ZnO Nanorod Array Using a Novel Solution Method. J Phy Chem B 2005, 109:19263-19269.

17. Li J, Liu X, Ye Y, Zhou H, Chen J: Gecko-inspired synthesis of superhydrophobic ZnO surfaces with high water adhesion. Colloids Surf A 2011, 384:109-114.

18. Ding Y, Gao PX, Wang ZL: Catalyst-nanostructure interfacial lattice mismatch in determining the shape of VLS grown nanowires and nanobelts: a case of Sn/ZnO. J Am Chem Soc 2004, 126:2066-2072.

19. Xu C, Shin P, Cao L, Gao D: Preferential Growth of Long ZnO Nanowire Array and Its Application in Dye-Sensitized Solar Cells. J Phy Chem C 2009, 114:125-129.

20. Liu S, Li C, Yu J, Xiang Q: Improved visible-light photocatalytic activity of porous carbon self-doped $\mathrm{ZnO}$ nanosheet-assembled flowers. CrystEngComm 2011, 13:2533-2541.

21. Yu J, Yu X: Hydrothermal synthesis and photocatalytic activity of zinc oxide hollow spheres. Environ Sci Technol 2008, 42:4902-4907.

22. Yu H, Zhang Z, Han M, Hao X, Zhu F: A General Low-Temperature Route for Large-Scale Fabrication of Highly Oriented ZnO Nanorod/ Nanotube Arrays. J Am Chem Soc 2005, 127:2378-2379.

23. Cheng B, Shi, Russell-Tanner JM, Zhang L, Samulski ET: Synthesis of Variable-Aspect-Ratio, Single-Crystalline ZnO Nanostructures. Inorg Chem 2006, 45:1208-1214

24. Wang C, Shen E, Wang E, Gao L, Kang Z, Tian C, Lan Y, Zhang C: Controllable synthesis of $\mathrm{ZnO}$ nanocrystals via a surfactant-assisted alcohol thermal process at a low temperature. Mater Lett 2005, 59:2867-2871.

25. Liu B, Zeng HC: Hydrothermal Synthesis of $\mathrm{ZnO}$ Nanorods in the Diameter Regime of $50 \mathrm{~nm}$. J Am Chem Soc 2003, 125:4430-4431.

26. Tan WK, Razak KA, Ibrahim K, Lockman Z: Oxidation of etched Zn foil for the formation of $\mathrm{ZnO}$ nanostructure. J Alloys Compd 2011, 509:6806-6811

27. Yang H, Song Y, Li L, Ma J, Chen D, Mai S, Zhao H: Large-Scale Growth of Highly Oriented $\mathrm{ZnO}$ Nanorod Arrays in the $\mathrm{Zn}-\mathrm{NH}_{3} \cdot \mathrm{H}_{2} \mathrm{O}$ Hydrothermal System. Cryst Growth Des 2008, 8:1039-1043.

28. Li B, Wang Y: Facile Synthesis and Enhanced Photocatalytic Performance of Flower-like ZnO Hierarchical Microstructures. J Phy Chem C 2009, 114:890-896.

29. Wang Y, Li X, Lu G, Quan X, Chen G: Highly Oriented 1-D ZnO Nanorod Arrays on Zinc Foil: Direct Growth from Substrate, Optical Properties and Photocatalytic Activities. J Phy Chem C 2008, 112:7332-7336.

30. Li C, Hong G, Wang P, Yu D, Qi L: Wet Chemical Approaches to Patterned Arrays of Well-Aligned ZnO Nanopillars Assisted by Monolayer Colloidal Crystals. Chem Mater 2009, 21:891-897.

31. Tian Y, Hu C, Xiong Y, Wan B, Xia C, He X, Liu H: ZnO Pyramidal Arrays: Novel Functionality in Antireflection. J Phy Chem C 2010, 14:10265-10269.

32. Panchakarla $L S$, Govindaraj $A$, Rao CNR: Formation of ZnO Nanoparticles by the Reaction of Zinc Metal with Aliphatic Alcohols. J Cluster Sci 2007, 18:660-670

33. Panchakarla LS, Shah MA, Govindaraj A, Rao CNR: A simple method to prepare $\mathrm{ZnO}$ and $\mathrm{Al}(\mathrm{OH})_{3}$ nanorods by the reaction of the metals with liquid water. J Solid State Chem 2007, 180:3106-3110.

34. Yan C, Xue D: Solution growth of nano- to microscopic ZnO on Zn. J Cryst Growth 2008, 310:1836-1840.

35. Bianco Prevot A, Baiocchi C, Brussino MC, Pramauro E, Savarino P, Augugliaro V, Marci G, Palmisano L: Photocatalytic Degradation of Acid Blue 80 in Aqueous Solutions Containing $\mathrm{TiO}_{2}$ Suspensions. Environ Sci Technol 2001, 35:971-976.

36. Mai FD, Chen CC, Chen JL, Liu SC: Photodegradation of methyl green using visible irradiation in $\mathrm{ZnO}$ suspensions: Determination of the reaction pathway and identification of intermediates by a high-performance liquid chromatography-photodiode arrayelectrospray ionization-mass spectrometry method. J Chromatogr A 2008, 1189:355-365.-

doi:10.1186/1752-153X-6-63

Cite this article as: Chung et al.: Determining the degradation efficiency and mechanisms of ethyl violet using HPLC-PDA-ESI-

MS and GC-MS. Chemistry Central Journal 2012 6:63.

Publish with ChemistryCentral and every
scientist can read your work free of charge
"Open access provides opportunities to our
colleagues in other parts of the globe, by allowing
anyone to view the content free of charge."
W. Jeffery Hurst, The Hershey Company.
- available free of charge to the entire scientific community
- peer reviewed and published immediately upon acceptance
- cited in PubMed and archived on PubMed Central
- yours - you keep the copyright
submit your manuscript here:
http://www.chemistrycentral.com/manuscript/

